\title{
Effect of fatty acids on bilirubin conjugation
}

\author{
T. HARGREAVES \\ From the Area Pathology Laboratory, Exeter, Devon
}

\begin{abstract}
Hargreaves, T. (1973). Archives of Disease in Childhood, 48, 446. Effect of fatty acids on bilirubin conjugation. The effect of fatty acids on bilirubin conjugation has been studied. Unsaturated fatty acids containing 18 to 20 carbon atoms decreased the rate of conjugation in rat liver slices and microsomes, probably by inhibiting glucuronyl transferase. Since fatty acids may be an important source of energy for the young infant, the relation of these findings to breast milk jaundice is discussed.
\end{abstract}

Breast-fed infants have a higher incidence of hyperbilirubinaemia in the first week of life than infants who are bottle fed (Arthur, Bevan, and Holton, 1966). In certain infants it has been noted that breast feeding is associated with a prolonged unconjugated hyperbilirubinaemia (breast milk jaundice). This type of jaundice is associated with an inhibitor of bilirubin conjugation in vitro in the maternal milk.

Free fatty acids derived from triglycerides in milk may be an important source of energy for the young infant (Hahn and Koldovsky, 1966). One of the advantages of human milk in infant nutrition is that it contains a lipase which liberates free fatty acids from triglycerides so they are available before the digestive phase in the intestine (György, 1971). Since certain breast milks inhibit bilirubin conjugation in vitro, it seemed important to determine whether fatty acids inhibit conjugation and so possibly are the cause of this jaundice.

\section{Materials and methods}

Male albino Wistar rats weighing 200 to $250 \mathrm{~g}$ were used. Bilirubin conjugation by rat liver slices was determined from the amount of direct reacting bilirubin in the incubation medium by the method of Lathe and Walker (1958). The total and conjugated bilirubin contents of liver slices were determined by the method of Hargreaves (1965) with one modification: the bilirubin estimations were performed at $4{ }^{\circ} \mathrm{C}$ throughout. The rate of bilirubin conjugation in rat liver microsomes was determined by method II of Van Roy and Heirwegh (1968) in the presence of $2.0 \mathrm{mmol}$ uridine 5 '-pyrophosphate glucuronic acid (UDPGA).

The acids investigated were among those reported to be present in breast milk (Insull and Ahrens, 1959;

Received 17 October 1972.
Foman, 1967). These were the saturated fatty acids butyric $\left(\mathrm{C}_{4}\right)$, caproic $\left(\mathrm{C}_{6}\right)$, caprylic $\left(\mathrm{C}_{8}\right)$, capric $\left(\mathrm{C}_{10}\right)$, lauric $\left(\mathrm{C}_{12}\right)$, myristic $\left(\mathrm{C}_{14}\right)$, palmitic $\left(\mathrm{C}_{18}\right)$, stearic $\left(\mathrm{C}_{18}\right)$, and arachidic $\left(\mathrm{C}_{20}\right)$ acids. The unsaturated fatty acids were oleic (9-octadecenoic), linoleic (9,12-octadecadienoic), linolenic (9,12,15-octadecatrienoic), $\gamma$-linolenic (6,9,12-octadecatrienoic), gondoic (11-eicosaenoic), 11,14-eicosadienoic, 11,14,17-eicostrienoic, arachidonic (5,8,11,14-eicosatetraenoic), and 5,8,11,14,17-eicosapentaenoic acids.

In the slice experiments all the fatty acids were added to the incubation flasks to give a final concentration of $1 \mathrm{mmol} / 1$. , but the unsaturated fatty acids were investigated further in concentrations of $1,2,5$, and $10 \mathrm{mmol} / 1$. In the microsome experiments all acids were added in final concentrations of $0 \cdot 01,0 \cdot 1,1 \cdot 0$, and $10.0 \mathrm{mmol} / 1$. All results are the mean of at least three experiments. ${ }^{\star}$

\section{Results}

Saturated fatty acids. Addition of saturated fatty acids to the conjugation reaction using rat liver slices did not produce inhibition at a concentration of $1 \mathrm{mmol} / \mathrm{l}$. In rat liver microsomes inhibition did not occur at a concentration of 10 $\mathrm{mmol} / \mathrm{l}$. The acids investigated were butyric, caproic, caprylic, capric, lauric, myristic, palmitic, stearic, and arachidic acids.

Unsaturated fatty acids. Addition of the unsaturated fatty acids inhibited bilirubin conjugation in rat liver slices and microsomes.

The effect of the $\mathrm{C}_{18}$ unsaturated fatty acids on bilirubin conjugation in rat liver slices is seen in Fig. 1. Oleic, linoleic, and linolenic acids have

^Fatty acids were obtained from Koch-Light Laboratories Ltd. and Sigma Chemical Company Ltd.; UDPGA from Sigma Chemical Company Ltd.; bilirubin and all other reagents from British Drug Houses Ltd. 


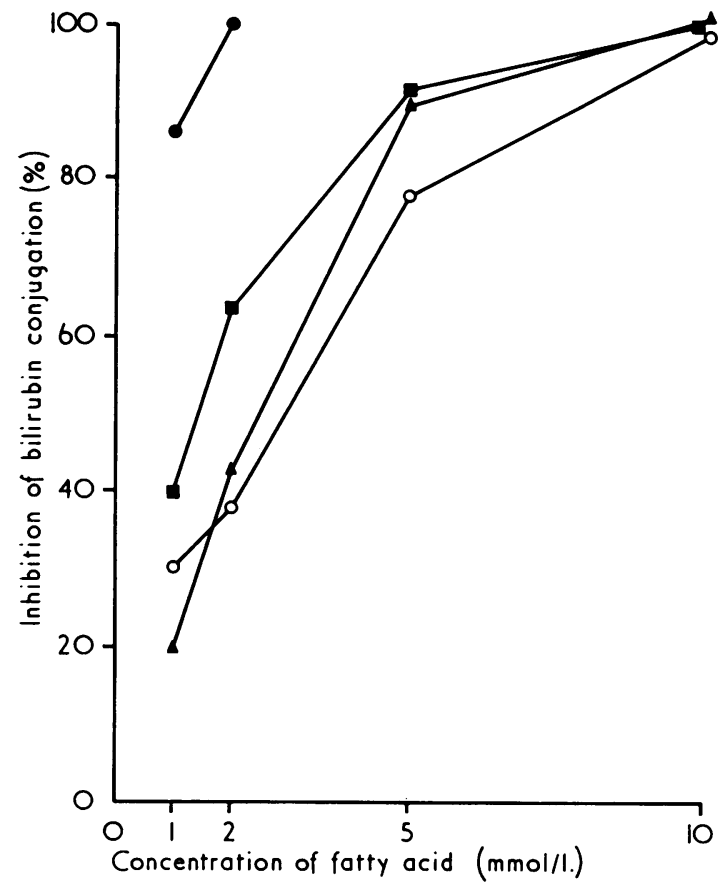

Fig. 1.-Effect of $C_{18}$ unsaturated fatty acids on bilirubin conjugation in rat liver slices. $O$ oleic $\left(C_{18: 1}\right)$ acid; - linoleic $\left(C_{18: 2}\right)$ acid; $\Delta$ linolenic $\left(C_{18: 3}\right)$ acid; $\gamma$-linolenic $\left(C_{18: 3}\right)$ acid.

similar inhibitory effects, but $\gamma$-linolenic $(6,9,12$ octadecatrienoic) acid inhibits the reaction more strongly than the other acids. The effect of the $\mathrm{C}_{20}$ unsaturated fatty acids is seen in Fig. 2. The relative inhibitory strength of the $\mathrm{C}_{20}$ unsaturated fatty acids is, in decreasing order, $5,8,11,14,17$ eicosapentaenoic $\left(\mathrm{C}_{20: 5}\right)$ acid $>5,8,11,14$-eicosatetraenoic (arachidonic) $\left(\mathrm{C}_{20: 4}\right)$ acid $>11,14,17-$ eicosatrienoic $\left(\mathrm{C}_{20: 3}\right)$ acid $>11,14$-eicosadienoic $\left(\mathrm{C}_{20: 2}\right)$ acid $>11$-eicosaenoic $\left(\mathrm{C}_{20: 1}\right)$ acid, indicating a possible correlation between inhibition and extent of unsaturation of the fatty acid.

In liver slices the reactions leading to the synthesis of bilirubin glucuronide can be considered in stages. (1) Uptake of bilirubin from the medium, (2) passage of bilirubin to the conjugating mechanism, (3) transfer of glucuronic acid to bilirubin which is catalysed by a microsomal enzyme (UDP glucuronate transferase (acceptor unspecific) EC 2.1.4.17), and (4) excretion of bilirubin glucuronide from the liver cell to the medium. If there is inhibition of glucuronyl transferase, then the amount of conjugated bilirubin in the medium and in the slice is decreased com- pared with the control. Addition of the unsaturated fatty acids tested decreased the amount of conjugated bilirubin in the liver slice compared with the controls, as well as decreasing the conjugated bilirubin in the medium. Fig. 3 shows the effect of $\mathrm{C}_{18}$ unsaturated fatty acids on the conjugated bilirubin content of the slices, and Fig. 4 shows the effect of adding unsaturated $\mathrm{C}_{20}$ fatty acids.

The transferase stage of bilirubin conjugation was examined in rat liver microsomes with added UDPGA. The effect of adding unsaturated $\mathrm{C}_{18}$ fatty acids is seen in Fig. 5. The relative inhibitory strength of the unsaturated acids was, in decreasing order, $\gamma$-linolenic $\left(\mathrm{C}_{18: 3}\right)$ acid $>$ linolenic $\left(\mathrm{C}_{18: 3}\right)$ acid $>$ linoleic $\left(\mathrm{C}_{18: 2}\right)$ acid $>$ oleic $\left(\mathrm{C}_{18: 1}\right)$ acid. This may indicate a correlation between inhibition and extent of unsaturation. Fig. 6 shows the effect of unsaturated $\mathrm{C}_{20}$ acids on bilirubin conjugation by rat liver microsomes.

\section{Discussion}

The effect of fatty acids on bilirubin conjugation has been determined because they are an important

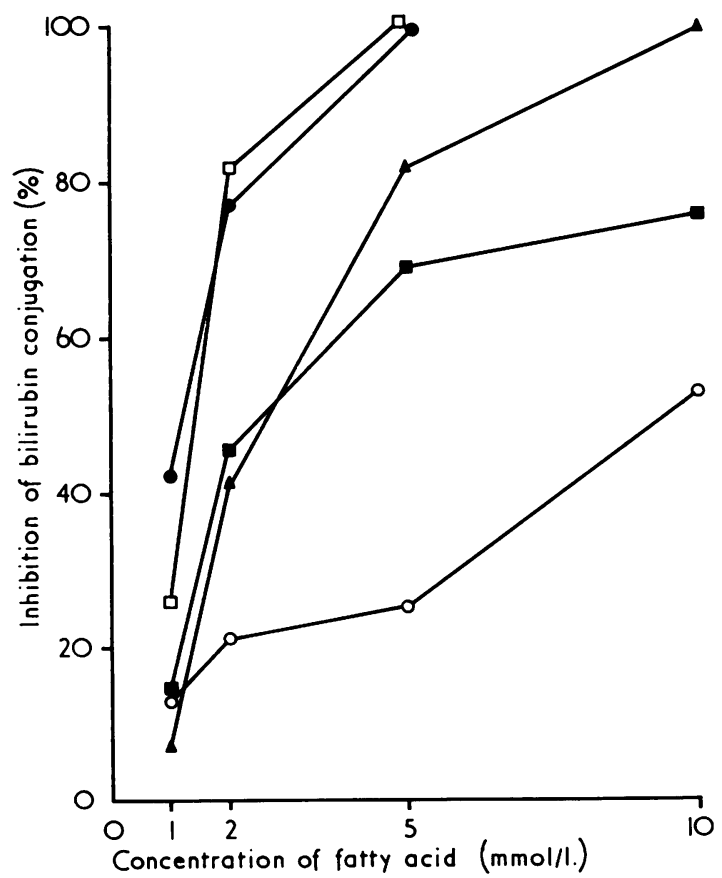

FIG. 2.-Effect of $C_{20}$ unsaturated fatty acids on bilirubin conjugation in rat liver slices. 0 11-eicosaenoic $\left(C_{20: 1}\right)$ acid; 11,14-eicosadienoic $\left(C_{20: 2}\right)$ acid; $\triangle 11,14,17-$ eicosatrienoic $\left(C_{20: 3}\right)$ acid; $5,8,11,14$-eicosatetraenoic $\left(C_{20: 4}\right)$ acid; $\square 5,8,11,17$-eicosapentaenoic $\left(C_{20: 3}\right)$ acid. 
constituent of the diet of breast-fed infants. It is known that breast-fed infants have a higher incidence of jaundice and it may be that there is a relation between these observations.

Unsaturated fatty acids inhibit bilirubin conjugation in in vitro preparations. Breast milk from mothers of children with breast milk jaundice also inhibits bilirubin conjugation, as do a number control milks (Hargreaves, 1970). The inhibitory substance has been thought to be $3 a, 20 \beta$-pregnanediol (Arias et al., 1964), though Hargreaves and Piper (1971) pointed out that the effect of this steroid on in vitro preparations was not the same as inhibitory breast milk. Breast milk decreased the amount of conjugated bilirubin in the liver slice as well as reducing the rate of conjugation, but $3 a$, $20 \beta$-pregnanediol did not decrease the conjugated bilirubin content of rat liver slices. The unsaturated fatty acids investigated here decreased the conjugated bilirubin content of rat liver slices as well as the rate of conjugation. The inhibitory effect of fatty acids on conjugation by rat liver microsomes is similar to that on slices. Though this suggests that the effect on liver slices is due to inhibition of transferase, it may be noted that oleic acid and some

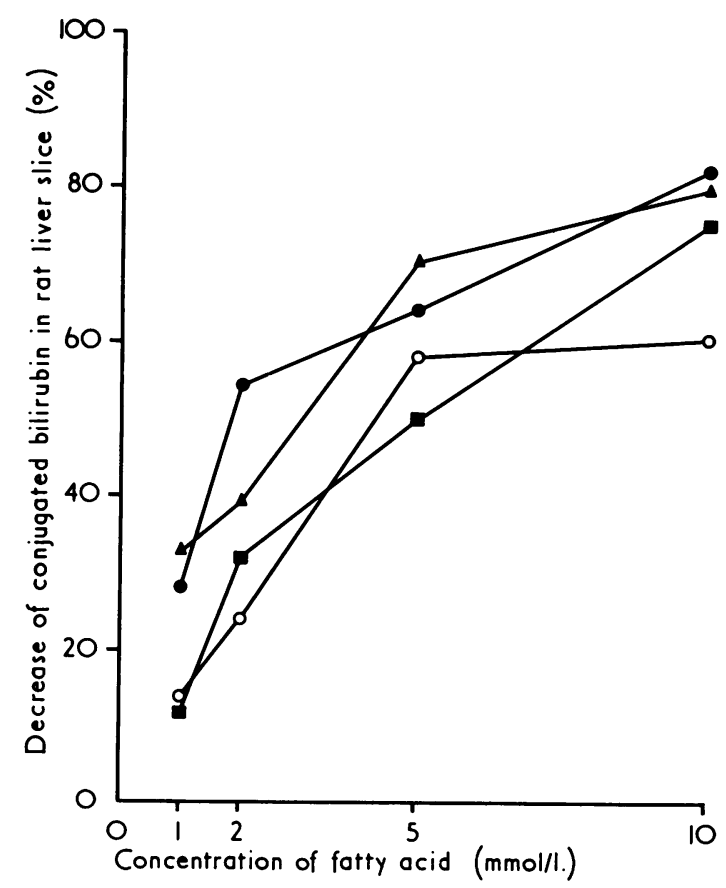

Fig. 3.-Effect of $C_{18}$ unsaturated fatty acids on conjugated bilirubin content of rat liver slices. $O$ oleic $\left(C_{18: 1}\right)$ acid; linoleic $\left(C_{18: 2}\right)$ acid; $\Delta$ linolenic $\left(C_{18: 3}\right)$ acid; - $\gamma$-linolenic $\left(C_{18: 3}\right)$ acid.

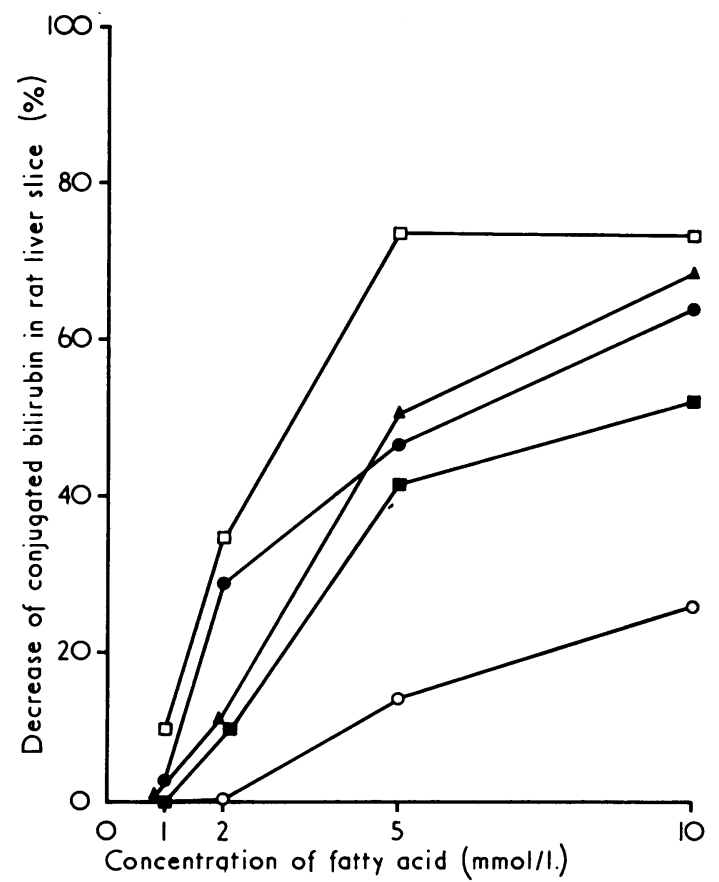

Fig. 4.-Effect of $C_{20}$ unsaturated fatty acids on conjugated bilirubin content of rat liver slices. $011-$ eicosaenoic $\left(C_{20: 1}\right)$ acid; 11,14-eicosadienoic $\left(C_{20: 2}\right)$ acid; $\triangle 11,14,17-$ eicosatrienoic $(20: 3)$ acid; $\bullet$ 5,8,11, 14-eicosatetraenoic $\left(C_{20: 4}\right)$ acid; $\square$ 5,8,11,14,17-eicosapentaenoic $\left(C_{20: 5}\right)$ acid.

other unsaturated fatty acids have a greater inhibitory effect on rat liver slices than on microsomes, suggesting that an earlier part of the bilirubin transport pathway, such as the $\mathrm{Y}$ protein, may be affected (Levi, Gatmaitan, and Arias, 1969).

The mode of action of unsaturated fatty acids on bilirubin conjugation is closely mirrored by their effect on other microsomal enzyme systems (Di Augustine and Fouts, 1969). Unsaturated fatty acids bind to proteins with great affinity and these authors suggested that a stable microsomalapoenzyme complex is formed since linoleic acid is not metabolized when added in vitro to rat hepatic microsomes. It was also shown that there was a possible correlation between inhibition of microsomal drug-metabolizing enzymes and the degree of unsaturation of the fatty acid. A straight chain fatty acid (arachidic acid) did not produce the same spectral changes in rat liver microsomes as did the unsaturated acids. The effect on drug metabolism was independent of secondary peroxidative products of the fatty acid. This is important since 


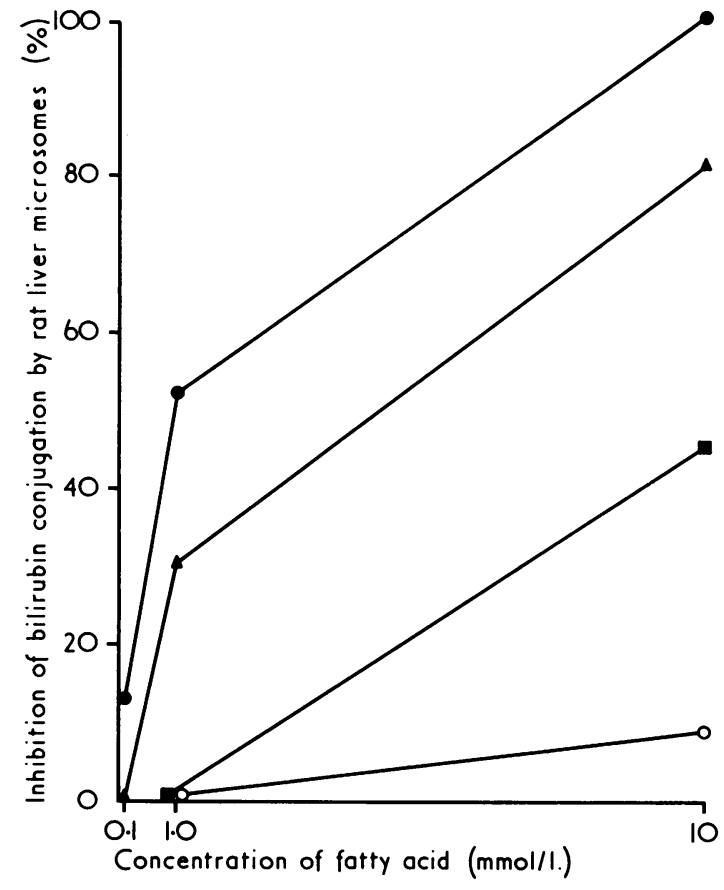

FIg. 5.-Effect of $C_{18}$ unsaturated fatty acids on bilirubin conjugation by rat liver microsomes. $O$ oleic $\left(C_{18: 1}\right)$ acid; 1 linoleic $\left(C_{18: 2}\right)$ acid; $\Delta$ linolenic $\left(C_{18: 3}\right)$ acid; $\gamma$-linolenic $\left(C_{18: 3}\right)$ acid.

lipid peroxidation decreases the activity of membrane-bound enzymes of the endoplasmic reticulum (Wills, 1971).

Breast milk jaundice may be the result of the interaction of a number of factors. The addition of milk to the liver slice system may be calculated (Fomon, 1967) to produce fatty acid concentrations as triglycerides of $3.4 \mathrm{mmol} / \mathrm{l}$. oleic acid, 0.8 mmol linoleic acid, and $0.04 \mathrm{mmol}$ linolenic acid. The composition of breast milk lipids depends on maternal calorie intake and the composition of dietary fats. If too few calories are taken, then the fatty acids in milk resemble adipose tissue; if excess calories are taken, then synthesis of fat from carbohydrate occurs and the milk is poor in unsaturated fatty acids but rich in $\mathrm{C}_{12}, \mathrm{C}_{14}, \mathrm{C}_{16}$ saturated fatty acids. The lipid composition of breast milk can rapidly change to mimic dietary fats often within 2 or 3 days (Insull and Ahrens, 1959).

It is interesting to speculate why human but not cow's milk is inhibitory. Human milk contains more linoleic acid (Fomon, 1967), also a lipase active at $4{ }^{\circ} \mathrm{C}$ and in deep frozen milk
(György, 1971). It has been observed that the inhibitory activity of breast milk on conjugation increases in milk kept in the deep freeze, but not in autoclaved milk (Hargreaves, 1970). It is possible that this may be due to the release of free fatty acids so causing the breast milk to inhibit bilirubin conjugation.

Unsaturated fatty acids inhibit bilirubin conjugation in vitro, the inhibition generally increasing with the degree of unsaturation. It is possible that an unusually high concentration of one of these acids in maternal milk may be a factor in producing breast milk jaundice.

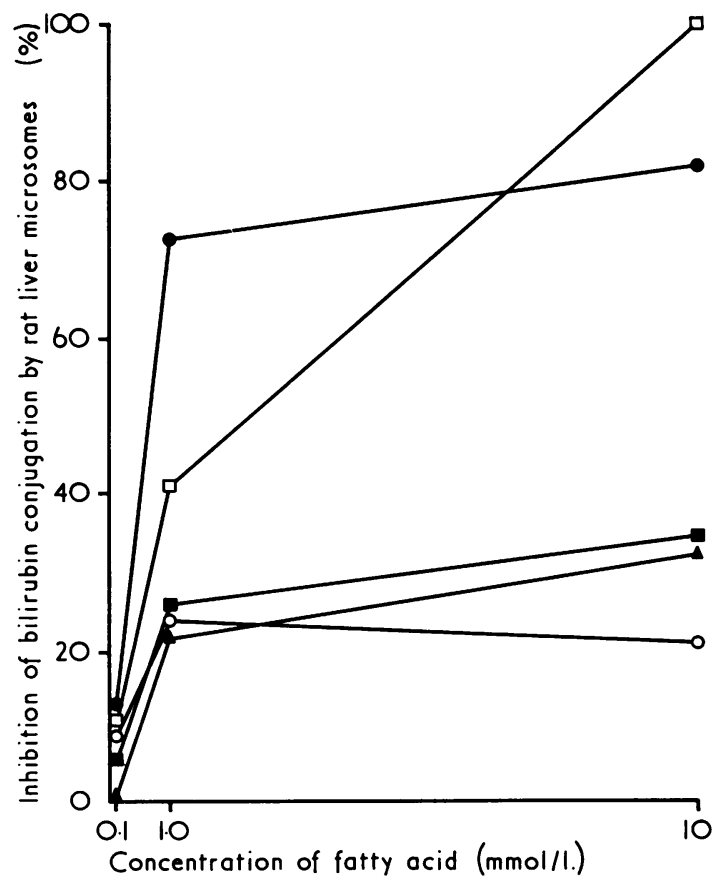

FIG. 6.-Effect of $C_{20}$ unsaturated fatty acids on bilirubin conjugation by rat liver microsomes. O 11-eicosaenoic $\left(C_{20: 1}\right)$ acid; 11,14 -eicosadienoic acid; $\Delta$ 11,14,17eicosatrienoic acid $\left(C_{20: 3}\right)$ acid; $5,8,11,14$-eicosatetraenoic acid; $\square \quad 5,8,11,14,17$-eicosapentaenoic $\left(C_{20: 5}\right)$ acid.

I thank Mrs. C. Howard and Miss K. Taylor for their expert technical assistance, and the Northcott Devon Medical Foundation for their generous financial support.

REFERENCES

Arias, I. M., Garner, L. M., Seifter, S., and Furman, M. (1964). Prolonged neonatal unconjugated hyperbilirubinemia associated with breast feeding and a steroid pregnane-3 $\alpha, 20 \beta$-diol in maternal milk that inhibits glucuronide formation in vitro. fournal of Clinical Investigation, 43, 2037. 
Arthur, L. J. H., Bevan, B. R., and Holton, J. B. (1966). Neonatal hyperbilirubinaemia and breast feeding. Developmental Medicine and Child Neurology, 8, 279.

Di Augustine, R. P., and Fouts, J. R. (1969). The effects of unsaturated fatty acids on hepatic microsomal drug metabolism and cytochrome P450. Biochemical fournal, 115, 547.

Fomon, S. J. (1967). Infant Nutrition. W. B. Saunders, Philadelphia.

György, P. (1971). The uniqueness of human milk. Biochemical aspects. American fournal of Clinical Nutrition, 24, 970.

Hahn, P., and Koldovsky, O. (1966). Utilization of Nutrients During Post Natal Development. Pergamon, Oxford.

Hargreaves, T. (1965). The estimation of bilirubin in liver Clinica Chimica Acta, 11, 278.

Hargreaves, T. (1970). Breast-milk jaundice. British Medical fournal, 3, 647.

Hargreaves, T., and Piper, R. F. (1971). Breast milk jaundice. Effect of inhibitory breast milk and $3 \alpha, 20 \beta$-pregnanediol on glucuronyl transferase. Archives of Disease in Childhood, 46, 195.

Insull, W., and Ahrens, E. H., Jr. (1959). The fatty acids of human milk from mothers on diets taken ad libitum. Biochemical fournal, 72, 27.

Lathe, G. H., and Walker, M. (1958). The synthesis of bilirubin glucuronide in animal and human liver. Biochemical fournal, $70,705$.

Levi, A. J., Gatmaitan, Z., and Arias, I. M. (1969). Two hepatic cytoplasmic protein fractions, $\mathrm{Y}$ and $\mathrm{Z}$, and their possible role in the hepatic uptake of bilirubin, sulphobromophthalein and other anions. Fournal of Clinical Investigation, 48, 2156.

Van Roy, F. P., and Heirwegh, K. P. M. (1968). Determination of bilirubin glucuronide and assay of glucuronyltransferase with bilirubin as acceptor. Biochemical fournal, 107, 507.
Wills, E. D. (1971). Effects of lipid peroxidation on membranebound enzymes of the endoplasmic reticulum. Biochemical fournal, 123, 983.

Correspondence to Dr. T. Hargreaves, Area Department of Pathology, Church Lane, Heavitree, Exeter, Devon EX2 5AD.

(Note added in proof.) Since this paper was submitted Bevan and Holton (1972) have investigated the effect of inhibitory breast milk and fatty acids on bilirubin conjugation in rat liver slices. They have shown that samples of breast milk containing $15 \mathrm{mmol} / \mathrm{l}$. or more of free fatty acids were highly inhibitory. The effect of the unsaturated fatty acids investigated on conjugation was similar to the results obtained in the present paper. They found, however, that certain saturated fatty acids inhibited conjugation though the concentrations used were higher than in the present investigation.

\section{REFERENCE}

Bevan, B. R., and Holton, J. B. (1972). Inhibition of bilirubin conjugation in rat liver slices by free fatty acids, with relevance to the problem of breast milk jaundice. Clinica Chimica Acta, $14,101$. 